\section{IMPLICAÇÕES DO USO DAS MÍDIAS SOCIAIS NAS FESTAS TRADICIONAIS E AS (RE)SIGNIFICAÇÕES DO LUGAR}

\author{
Implications of Social Media utilization at Traditional Festivities and Place \\ $(\mathrm{Re})$ significations
}

\author{
Jéssica Soares de Freitas \\ Maria Geralda de Almeida** \\ *Doutoranda no PPGeo/IESA/UFG - jessicasoaresfreitas@gmail.com \\ **Professora do PPGeo/IESA/UFG - mgdealmeida10@gmail.com
}

Recebido em 20/06/2019. Aceito para publicação em 30/07/2019.

Versão online publicada em 10/09/2019 (http://seer.ufrgs.br/paraonde)

\begin{abstract}
Resumo:
A considerar as mudanças cada vez mais rápidas nas tecnologias da informação entende- se que as festas tradicionais, que envolvem o lugar da comunidade estão também sujeitadas a esses processos dinâmicos da contemporaneidade. Nesse sentido, o artigo intenta compreender de que forma os sujeitos se apropriam de tais lógicas ao mesmo passo em que também se envolvem em veredas desconhecidas da mídia, especialmente das redes sociais. A construção desse envolveu leitura e apreensão de conceitos e teorias acerca das festas e das tecnologias da informação e comunicação a fim de se discutir, de forma teórica, as possibilidades que são abertas por tais nexos. Tais embasamentos se derivam de discussões realizadas na Geografia Cultural, especialmente a brasileira, inserida no âmbito dos estudos pós-modernos, a discutir a (re)significação da tradição por meio da inserção das tecnologias.
\end{abstract}

Palavras-chave: Tecnologia da Informação e Comunicação; Festas tradicionais; Lugar.

\begin{abstract}
:
Taking into consideration the ever faster changes in the technologies of information, it's understood that the traditional festivities, which envelops community's place are also subject to these dynamic processes of contemporarity. In this sense, the essay also intents to comprehend in what ways the subjects appropriates these logics at the same pace as they involve in the unknown regions of the media, specially the social networks. The construction of this essay involved the reading and apprehension of concepts and theories about the festivities and technologies of information and communication in order to discuss, in a theoretical way, the possibilities opened up by these nexus. These groundings derives from discussions situated at the Cultural Geography, specially Brazilian, inserted at the spectrum of postmodern studies, to discuss the (re)signification of tradition by the insertion of technologies.
\end{abstract}

Key-words: Technology of information and communication; Traditional Festivities; Place.

\section{Introdução}

Sendo o espaço complexo e dinâmico, o encontro entre o antigo e o novo é constante, principalmente nos momentos atuais da vida cotidiana. Pela curiosidade geográfica intenta-se compreender como as mídias são incorporadas nas festas tradicionais na contemporaneidade e como (se) tais (re)significações alteram seus sentidos de lugar. Realiza-se a partir de estudos bibliográficos de festa, lugar e tecnologia, com foco nas TIC's, mais especificamente internet.

Para alcançar o pretendido é adotada uma perspectiva pós-moderna científica, de modo a considerar a interdisciplinaridade da geografia com outras áreas do conhecimento (CLAVAL, 2002). A ponderar que o uso das mídias sociais faz parte do cotidiano da maioria dos sujeitos, 
entende-se que as práticas culturais centenárias são afetadas por essas novas configurações. A globalização e a dinamogenia das técnicas e tecnologias influenciaram àqueles que as dominam e os que estão à margem das lógicas hegemônicas.

Esses novos nexos são permeados principalmente pelas tecnologias mais rápidas, que diminuem as distâncias e aumentam a facilidade de se conhecer diferentes culturas e sociabilidades. Se as festas têm uma importante função na relação entre o sujeito e o meio (BEZERRA, 2008), ao extrapolarem as fronteiras físicas da festa e realçarem suas identidades, esses sujeitos conseguem alcançar diferentes reações e evidenciam seus sentidos de lugar. Isso se manifesta em relação à festa da qual participa e com sua comunidade que é representada, de modo a estabelecer outras relações de valoração simbólica de seu(s) lugar(es).

O sentimento de pertencimento torna-se um aspecto significativo, pois, para que os sujeitos possam permanecer vívidos na festa e na comunidade, tal sentido é primordial para manterem vínculos com o lugar (SANTOS; KINN, 2009). A utilização das mídias sociais é evidenciada diferentes festas, sendo algumas delas com perfil no Facebook e em outras mídias sociais. Ressalta-se que as utilizações desses modos de tecnologia provêm desde a era do rádio, quando algumas comunidades utilizavam tal ferramenta para divulgar suas festividades. No entanto, tais práticas podem vir a transgredir alguns sentidos da festa, ao mesmo passo em que se mostra uma permanência da mesma e uma (re)significação para que se possa continuar com tais práticas.

Para a concepção deste estudo foram realizadas leituras acerca das mudanças sociais contemporâneas em relação às mídias sociais e festas; bem como acerca dos conceitos e teorias geográficas, principalmente sobre pós- modernidade e abordagem cultural na geografia a constituir, dessa forma, em um trabalho teórico. Com tais delineamentos o objetivo foi refletir nas relações pós-modernas que há na atualidade, em especial nas festas mais tradicionais. Certamente estas reflexões poderão confluir para um levantamento teórico-crítico acerca de tais pensamentos.

\section{RELAÇÕES PÓS-MODERNAS E GEOGRAFIA CULTURAL NAS FESTAS}

Primeiramente, entende-se que a realidade vivida na contemporaneidade Segundo Souza Santos (2006, p. 195), "a própria teoria tem de se adequar às condições atuais do mundo atual e representar uma relação entre o novo e seu significado original, e as coisas velhas com o seu novo significado". Ao considerar o dinamismo que a sociedade atual apresenta, a abordagem pós-moderna se faz presente ao possibilitar análises mais amplas que se desprendem desse ou daquele modelo científico. Essa perspectiva se faz ciente de possíveis divergências irreconciliáveis e estabelece dialogias a partir de pontos de contato (ALMEIDA, 2013).

Outrossim, a proposta de pesquisa se encaixa no campo da abordagem cultural em Geografia, que se renova nos últimos anos, principalmente a partir da década de 1990 no Brasil (CLAVAL, 2012). A preocupação da geografia cultural com as manifestações dos sujeitos e sua ação no mundo, tanto individualmente quanto coletivamente, corroboram para com a proposta, pois busca compreender o que não se vê de imediato; no caso, as relações das festas tradicionais com os elementos digitais que transformam suas espacialidades.

Conforme Almeida (2013, p. 46), "a geografia está presente nas atitudes e nos conhecimentos que sempre mobilizamos em nosso cotidiano, nas práticas e fundamentos considerados pelos empreendedores para suas ações e produções". O uso das mídias sociais faz parte do hodierno da maioria dos sujeitos e, consequentemente, em meio a práticas culturais centenárias que são influenciadas por essas novas configurações.

As ações cotidianas de outrora se entrelaçam com as de hoje, a se manter renovada. Neste sentido, Claval (2010, p. 63), aponta que, "la dinámica actual del pensamiento geográfico 
refleja las rápidas transformaciones de un mundo de tan brusca globalización que la hizo a la evolución de las instituciones y de la regulaciones". A globalização e a dinamogenia das técnicas e tecnologias influenciaram àqueles que as dominam e os que estão à margem das lógicas hegemônicas.

Esses novos nexos são permeados principalmente pelas tecnologias mais rápidas, que diminuem as distâncias e aumentam a facilidade de se conhecer diferentes culturas e sociabilidades. Segundo Jansson (2005, p. 12), "new technologies enable not only new forms of communicative practices; they also impose the adjustment of spatial practices according to the anticipated presence and influence of new means of communication". As práticas culturais e sociais são transformadas de acordo com as tecnologias da comunicação, no caso, as mídias sociais.

Outra lógica é instaurada. Conforme Mafessoli (2008, p. 23), "as pessoas não querem só informação na mídia, mas também e fundamentalmente ver-se, ouvir-se, participar, contar o próprio cotidiano para si mesmas e para aqueles com quem convivem". Os sujeitos pretendem se fazer ouvir. Eles querem falar, serem vistos e, nessa mesma lógica, desejam que suas práticas também sejam observadas e reconhecidas.

Se as festas têm, conforme Bezerra (2008, p. 7), "importante papel na relação entre o homem e o meio, pois estas manifestações sempre refletiram o modo como os grupos sociais pensam, percebem e concebem seu ambiente, valorizam mais ou menos certos lugares", ao extrapolarem as fronteiras físicas da festa e realçarem suas identidades por meio de paisagens digitais, esses sujeitos conseguem alcançar diferentes reações e evidenciam seus sentidos de lugar. Isso se manifesta em relação à festa da qual participa e com sua comunidade que é representada, de modo a estabelecer outras relações de valoração simbólica de seu(s) lugar(es).

O sentimento de pertencimento torna-se um aspecto significativo, pois, para que esses sujeitos possam permanecer vívidos na festa e na comunidade, tal sentido é primordial para manterem vínculos com o lugar (SANTOS; KINN, 2009). Nesse olhar, como salientam Lôbo e Maia (2011, p. 151), "à medida que a festa vai adquirindo definição e significado para quem dela participa, ela não só está em como é um lugar carregado de simbologias, sentidos e conceitos". No caso, aqueles que mais se vinculam com a festa são os que fazem dela seu lugar, ou seja, aqueles que são da festa.

Destarte, é no lugar que os sujeitos se referenciam e efetivam suas representações. Serpa (2013, pp. 171-172) no campo fenomenológico afirma que, "os lugares clamam nossas afeições e obrigações, conhecemos o mundo através dos lugares nos quais vivemos". É pela festa, tida como lugar que muitas vezes os sujeitos reproduzem vínculos identitários. Ao visitarem festas distintas daquelas por eles vivenciadas por meio da memória dos mais velhos ou de sua própria, as lembranças viajam para sua festividade, elemento que também transforma o(s) lugar(es).

Na mesma vertente, Karjalainen (2012, p. 7) aponta que o lugar proporciona "um princípio organizador que nós chamamos de imersão de uma pessoa no mundo em torno de si. Em termos fenomenológicos, lugares são as partes da realidade espacial que foram reclamadas pelas intenções humanas". Lugar é a porção do espaço que recebe significado dos sujeitos e, dessa forma, a festa pode ser compreendida com a noção de lugar. Têm-se então que, conforme Tuan (2011, p. 05), "Iugar é qualquer localidade que tem significado para uma pessoa ou grupo de pessoas". As localidades, para além dos aspectos físicos, possuem imaterialidades que confluem no espaço e que são compreendidas pelos sujeitos enquanto lugar.

Relph (2014, p. 31), aponta que o lugar, já posto como porção do espaço que recebe significado "é um microcosmo. É onde cada um de nós se relaciona com o mundo e onde o mundo se relaciona conosco. O que acontece aqui, neste lugar, é parte de um processo em que o mundo inteiro está de alguma forma implicado". Devido aos novos meios de 
comunicação, que extrapolam fronteiras e inserem os sujeitos nos processos da globalização, essa configuração é econômica e social, elementos que ainda devem ser considerados para a compreensão da complexidade dos processos contemporâneos.

Outrossim, para reclamar um lugar para si, o sujeito se identifica com ele, define o lugar como seu. Para Seamon (2014, p. 17), "place identity phenomenologically relates to the process whereby people living in or otherwise associated with a place take up that place as a significant part of their world". A identidade de lugar transcorre pela identificação do sujeito com aquele determinado espaço. Relph (1976, p. 45), disserta que, "[...] not just the identity of a place that is important, but also the identity that a person or group has with that place, in particular whether they are experiencing it as insider or as an outsider". Aqueles que são da festa experienciam o lugar como insider, enquanto os que apreciam a festa são outsiders do lugar, mas também se identificam com ele.

Tais configurações são fundamentais para compreender as relações estabelecidas na festa em conjunto com as mídias sociais. O sujeito que é de dentro vê a festa diferente daquele que é de fora e, para tanto, intenta desvelar suas intenções e crenças, de modo a potencializar a gênese de paisagens que se recriam por meio dos sentidos e identidades de lugar.

Convém salientar que na perspectiva de Dardel e adotamos aqui, (2011, p. 32), "a paisagem não é, em sua essência, feita para se olhar, mas a inserção do homem no mundo, lugar de um combate pela vida, manifestação de seu ser com os outros, base de seu ser social". A paisagem é vivida pelos sujeitos, cada qual de sua maneira, com consciência própria revelada, ou não, de modo a interagir com as configurações socioespaciais. Ela é, em si, essa sobreposição sujeito-lugar que se manifesta na realidade geográfica.

Próximo da ideia desse autor, considera-se que Tuan nos alerta (2012, p. 21): "duas pessoas não veem a mesma realidade. Nem dois grupos sociais fazem exatamente a mesma avaliação do meio ambiente". Cada sujeito possui consciência própria, derivada de sua historicidade, de sua geograficidade (DARDEL, 2011), que influencia seu modo particular de observar o mundo, de decifrá-lo e, também, de compreender os ambientes.

Em confluência, Besse (2006, p. 92) pondera que a paisagem "se deixa ver, mas, além do simples pitoresco, na ordem própria da visibilidade que a paisagem oferece, o ser humano, ao situar-se nela visualmente, nela descobre as dimensões do seu ser". É na paisagem que o sujeito se conhece, percebe seu exterior e interior, revela suas intencionalidades como ser-nomundo.

No campo da Geografia Cultural Critica, segundo Cosgrove $(1998$, p. 13) "landscape is not merely the world we see, it is a construction, a composition of that world. Landscape is a way of seeing the world". A paisagem pode ser compreendida, na confluência destas perspectivas como um modo de ver, perceber e experienciar o mundo em sua geograficidade inerente. No entanto, com as mudanças tecnológicas, esse cosmo existencial é visto de outras maneiras, interceptado pelas tecnologias da comunicação.

Buttimer (1985, p. 180) pondera que, "o homem contemporâneo é móvel e pode experienciar o espaço mais vividamente em redes de interação social e comercial". Muitas vezes, a experiência de lugar ou da paisagem não se manifesta por completo, com o sujeito inserido fisicamente no espaço, mas por outros meios, pela intervenção ou introjeção tecnológica.

Nesse olhar, Claval (2010, p. 76) disserta que "las nuevas técnicas de comunicación, internet y el teléfono móvil en particular, crean nuevas maneras de vivir el espacio, de triunfar sobre la distancia y de jugar con las representaciones del espacio". Os celulares, em especial os smartphones, permitem aos sujeitos experienciar um mundo de possibilidades. É a potencialidade de estar em um lugar ao mesmo momento em que se localiza em outro. As tecnologias mediam nosso modo de ver e experienciar o mundo (IHDE, 2009).

No entanto, aqueles que estão inseridos também em outras lógicas entram, por vezes, em conflito com esse "mundo novo". Conforme Claval (2005, p. 91) "avec la modernization des techniques, il n'y a plus de place pour les savoir-faire traditionnels. Les cultures vernaculaires 
apparaissent de plus en plus comme des composantes axées sur la consommation des cultures globales". Ao mesmo passo que as tradições são transpassadas pelas novas configurações tecnológicas conduzidas pela globalização, muitos são os que desejam que seus saberes-fazeres sejam transmitidos para as próximas gerações.

Compreende-se a cultura como elemento dinâmico, que representa o passado, o presente e o futuro de cada grupo (CLAVAL, 2005). Nas festividades tradicionais, a influência da globalização é nítida, ainda que muitas vezes apontada como responsável por sua erosão. Para que ela não se perca, os sujeitos reestabelecem estratégias para sua manutenção, sendo uma delas o uso das mídias sociais, por meio das quais evidenciam suas lógicas de modo a destacar a importância de sua identidade e essa não está presa ao passado, e também se transforma.

$\mathrm{Na}$ congada em Uberlândia-MG, por exemplo, muitos participantes não se localizam na comunidade, nos "ternos", pela qual eles representam. Mas se sentem pertencentes a congada de modo a manterem vínculos com a mesma. Nesse sentido, em confluência com os ponderamentos de Kinn (2008, p. 76), "a manifestação do individual e do coletivo, na doação de tempo, conhecimentos e habilidades à Congada, aparece também como um conjunto de estratégias". Entre aqueles que vão à festa, mesmo que a maioria seja da própria comunidade, há os curiosos que não participam efetivamente dela, mas que a apreciam como outsider. Esse fato torna fundamental compreender a linha tênue entre a festa tradicional sua possível espetacularização.

Espetáculo é entendido não como um conjunto de imagens, mas, conforme Debord (1997, p. 14), "uma relação social entre pessoas, mediada por imagens" em que o sujeito é separado daquilo que antes era representação e se torna espetáculo por meio de sua reificação. As mídias sociais podem influenciar na transformação da festa em espetáculo, na medida em que as mesmas passam de mediadora do sujeito da festa para apenas o sujeito na festa, algo que pode ocorrer caso haja interesse de grupos hegemônicos.

\section{Considerações Finais}

Se considerarmos o que afirmamos no início, o mundo é um complexo e que passa por transformações cada vez mais profundas. Compreender a presença do tradicional no contemporâneo se faz necessário para compreender as novas geografias, especialmente no âmbito da abordagem cultural, que estão a surgir em diferentes aspectos. Dessa forma, esse artigo-ensaio é uma peça em um quebra-cabeça a ser montado ao longo de outros estudos.

As festas tradicionais, tais como festas religiosas são progressivamente expostas pelas novas tecnologias de formas a transformá-las, a modificar seu modo de existir e de sentir. No entanto, o saber-fazer da festa persiste, por mais que haja contraposições na mesma, pois os sujeitos que a movimentam, que são o coração da mesma, continuam a colocar seus próprios sentidos.

Dessa forma, por mais que os setores hegemônicos transformem as festividades ao colocarem campanha, patrocínios, ou mesmo construir identidades diferentes das alimentadas pelos sujeitos, seus mais profundos significados continuam. Os novos significados se juntam aos já construídos de modo contraditório.

As mídias sociais, dessa forma, ao se inserirem no contexto das festas tradicionais ao mesmo passo em que a modifica pode se tornar uma ferramenta para fortalecê-la perante as atuais mudanças. Para aqueles que participam ativamente da festa, um meio de fortalecer sua própria identidade e guardar memórias para o futuro. Já os que participam de forma menos ativa, mesmo que por vezes sua participação seja apenas no âmbito da espetacularização, coopera para a valorização de realidades que, por vezes, são ou estão escondidas. 


\section{Referências}

ALMEIDA, M. G. A Propósito do trato do invisível, do intangível e do discurso na Geografia Cultural. Anpege. v. 9, n. 11, p. 41-50, jan/jun. 2013.

TEIXEIRA, M. G.; ALMEIDA, M. G. A catira e a produção de uma identidade territorial no estado de Goiás. IN: MARQUES, L. M.(org.). Geografias do Cerrado: Sociedade, Espaço e Tempo no Brasil Central. Uberlândia: Edibrás, 2014, pp. 217- 241.

BEZERRA, A. C. A. Festa e Cidade: Entrelaçamentos e Proximidades. Espaço e Cultura. n. 23, p. 07-18. jan./jun. 2008.

BUTTIMER, A. Aprendendo o dinamismo do mundo vivido. In: CHRISTOFOLETTI, A. Perspectivas da geografia. São Paulo: Difel, 1985, pp. 165-193.

CLAVAL, P. "A volta do cultural” na Geografia. Mercartor. A. 01, n. 01, 2002. pp. 19- 28.

CLAVAL, P. A geografia cultural no Brasil. In: BARTHE-DELOIZY, F. (Org.); SERPA, A. (Org.). Visões do Brasil: estudos culturais em geografia. Salvador: EDUFBA; Edições L'Harmattan, 2012. pp. 11-26.

CLAVAL, P. La geografía em recomposición: objetos que cambian, giros múltiplos:? disolución o profundización? In: LINDÓN, A; HIERNAUX. Orgs.) Los giros de la geografia humana: Desafíos y horizontes. México: Anthopos, 2010. p. 63-82).

CLAVAL, P. Lieux de memoire. Revista Espaço e Cultura, UERJ, no 19, p. 89-106, 2005.

DARDEL, E. O Homem e a Terra. São Paulo: Perspectiva, 2011.

DEBORD, G. A sociedade do espetáculo. Rio de Janeiro: contraponto, 1997.

IHDE, D. Postphenomenology and tecnoscience: The Peking University Lectures. Albany: State University of New York Press, 2009.

JANSSON, A. For a Geography of Communication. Linköping Electronic University Press (Paper presented at the First National Conference in Cultural Studies, 13-15 June 2005).

KARJALAINEN, P. T. Lugar em Urwind: uma visão geográfica humanista. Geograficidade. v. 2, n. 2. Inverno 2012. pp. 4-22.

LÔBO, T. C; MAIA, C. E. S. Diferentes Formas de Estar na Festa. Textos escolhidos de cultura e arte populares. v. 8, n. 1, p. 149-160, mai. 2011.

MAFESSOLI. M. A comunicação sem fim (teoria pós-moderna da comunicação). In: MARTINS, M. F. (Org.); SILVA, J. M. (Org.). A genealogia do virtual: Comunicação, Cultura e tecnologias do Imaginário. 2ª ed. Porto Alegre: Sulina, 2008. pp. 20-32.

RELPH, E. Place and placelessness.London: Pion Limited, 1976.

RELPH, E. Reflexões Sobre a Emergência, Aspectos e Essência de Lugar. In: MARANDOLA JR., E. (Org.); WERTHER, H. (Org.); OLIVEIRA, L. (Org.). Qual o espaço do lugar?: geografia, epistemologia, fenomenologia. São Paulo: Perspectiva, 2014, pp. 17-32.

ROCHA, P. J; MONTARDO, S. P. Netnografia: incursões metodológicas na cibercultura. Revista da Associação Nacional dos programas de Pós-Graduação em Comunicação. Dez 2005. pp. 1-22.

SANTOS, B. S. Um discurso sobre as ciências. São Paulo: Cortez, 2006.

SANTOS, R. J; KINN, M. G. Festas: Tradições reinventadas nos espaços rurais dos cerrados de Minas Gerais. Espaço e Cultura. p. 58-71. n. 26, jul./dez. 2009.

SEAMON, D. Corpo-sujeito, rotinas espaço-temporais e danças-do-lugar. Geograficidade. v. 03, n. 02. Inverno 2013. pp. 04-18. 
SEAMON, D. Place Attachment and Phenomenology: The Synergistic Dynamism of place. In: MANZO, L. C. (Org.); DEVINE-WRIGHT, P. (Org.). Place Attachment: Advances in theory, methods and applications. New York: Routledge, 2014. pp. 12- 22.

SERPA, A. Paisagem, lugar e região: perspectivas teórico-metodológicas para uma geografia humana dos espaços vividos. GEOUSP - Espaço e Tempo. São Paulo, n. 33, 2013. pp. 168185.

TUAN, Y. Topofilia. Londrina: EdUel, 2012.

TUAN, Y. Espaço, tempo, lugar: um arcabauço humanista. Geograficidade. v. 01, n. 01. Inverno 2011. pp. 04-15. 